\title{
Use of Natural Products for Complementary Health Approaches among Psychiatric Outpatients in Japan
}

\author{
Mai Iwanaga ${ }^{1}$, Yuki Miyamoto ${ }^{1}$ and Norito Kawakami ${ }^{2 *}$ \\ ${ }^{1}$ Department of Psychiatric Nursing, Graduate School of Medicine, 7-3-1 Hongo, Bunkyo-Ku, Tokyo 113-0033, Japan \\ ${ }_{2}^{2}$ Department of Mental Health, Graduate School of Medicine, 7-3-1 Hongo, Bunkyo-Ku, Tokyo 113-0033, Japan
}

Received: April 20, 2018; Accepted: May 14, 2018; Published: May 18, 2018

*Corresponding author: NoritoKawakami, Department of Mental Health, Graduate School Of Medicine, The University Of Tokyo. 7-3-1 Hongo, BunkyoKu, Tokyo 113-0033, Japan, Tel: 81-03-5841-3521; Fax: 81-03-5841-3392; E-mail: nkawakami@m.u-tokyo.ac.jp

\begin{abstract}
Aim: The aim of this study was to clarify frequencies of nonprescribed natural product use and associated sociodemographic and other characteristics among psychiatric outpatients in Japan.

Methods: Using a self-report questionnaire, a cross-sectional survey was conducted of 253 outpatients aged 20 years or older at two psychiatric clinics in Tokyo, Japan. The questionnaire asked sociodemographic characteristics, the use of natural products (4 types), and medication adherence. Data were analyzed by multiple logistic regression predicting 12-month use of natural products on demographic variables.
\end{abstract}

Results: A total of 241 patients responded to the survey (response rate, 95\%). Statistical analysis was conducted for 189 respondents (females, 42\%; average age, 47 years old). A total of $104(55 \%)$ reported the use of any natural products: supplements/ health foods (41\%), herbal tea (20\%), aromatherapy (16\%), and overthe-counter Kampo (Japanese herbal medicines) (8\%). Significantly associated with natural product use were female (odds ratio [OR]: 4.28; 95\% confidence interval [CI]: 1.87-9.77) and having any religion (OR: 2.91; 95\% CI: $1.10-7.68$ ). Respondents aged 65 years or older had a significantly smaller probability of using natural products (OR: .15, 95\% CI: .03-.78). Among the respondents who reported carelessness with prescribed medications and stopping the drug when feeling worse, natural product users were fewer (OR: . 24, 95\% CI: .08-.76; OR: $.11,95 \%$ CI: .02-.69, respectively).

Conclusions: Use of natural products such as supplements and Kampo was found to be common among psychiatric outpatients in Japan. Natural product users reported higher as being careful with prescribed medications.

Keywords: Psychiatry; complementary health approaches; medication adherence; outpatient; communication; mental health.

\section{Introduction}

Complementary health approaches are non-mainstream practices and used by consumers together with conventional medicine distinguished from integrative health, which is a coordinated approach to the use of both non-mainstream and conventional practice together[1] such as Kampo (Japanese herbal medicine) which can be prescribed by doctors. One of the most common complementary health approaches is the use of natural products. According to the National Center for Complementary and Integrative Health in the U.S., natural products are defined as follows, "This group includes a variety of products, such as herbs (also known as botanicals), vitamins and minerals, and probiotics"[1]. In Japan, non-prescribed natural products are commonly known as supplements/health foods, herbs such as tea and essential oils, and over-the-counter Kampo (Japanese herbal medicine) [2-5].

These natural derived products seem to be safe; however, natural products can have several risks [6-8] such as a drug interaction with prescribed medications [6] and indirect health hazards that arise from not taking steps to receive appropriate and timely conventional medical care [7]. However, most patients do not disclose such use to their medical practitioners[9].

The use of natural products among people in general clinics or the community is common. For instance, in Japan, Shumer et al. Reported 32\% used herbs or supplements[2] and Hori et al. Found 35\%, 23\% and 19\% used vitamins, health foods including supplements and Kampo[3], respectively, in general outpatient clinics. In community-living people, Fukuda et al., reported the frequencies of supplements/health foods (male: 35\%, female: $47 \%$ ), aromatherapy/herbs (male: $2 \%$, female $7 \%$ ) and Kampo (male: 13\%, female: 19\%)[5].

In psychiatry, it is necessary for health care professionals to understand the reality of patients' natural product use and users' attitude toward conventional medicine. Many psychiatric patients use natural products [10-19] and at the same time, often are prescribed medications such as antipsychotic drugs. Of the attitudes toward conventional medicine, medication adherenceis especially important for psychiatric treatment. For example, there is a report that the longest period during which no medications appeared to be available was associated with a greater risk of hospitalization among psychiatric patients [20]. However, the association between medication adherence and the use of natural products is currently unknown. For these reasons, 
it is necessary to investigate the frequency and characteristics of patients' natural product use and the associations between natural product use and medication adherence in psychiatry.

The use of natural products among psychiatric patients in the world vary from country to country $[10-15,17,18]$. For example, the frequency of use of herbs and vitamins/minerals were found to be $4-26 \%$ and $1-16 \%$, respectively, in the U.S., Turkey and Taiwan [10-14]. A similar study in the U.S. indicated that 22 $58 \%$ of people who have psychiatric symptoms used biologically based therapies including herbs and vitamin therapy $[16,17]$. While these surveys reported on natural product use, the reports vary even in the same country due to varying study designs and different definitions. It is hard to presume that the frequency or characteristics of natural product use in Japan is the same as previous studies outside of Japan. However, there are no previous studies among psychiatric patients in Japan.

This cross-sectional study aimed to clarify: 1) frequency, demographic characteristics and correlates with natural product use, and 2) the association between medication adherence and natural product use among psychiatric outpatients in Japan.

\section{Methods}

\section{Study design and participants}

This cross-sectional survey was conducted at two psychiatric outpatient clinics located in the metropolitan city of Tokyo, Japan, from July to October 2016. A total of 253 patients were given selfreported questionnaires by researchers or medical staff in each clinic. Inclusion criteria were patients who received psychiatric outpatient treatment, and aged 20 years or older. Patients were excluded if psychiatrists determined that they were ineligible to participate in the survey due to their mental or physical condition. The questionnaire asked about twelve-month use of natural products, sociodemographic characteristics, and medication adherence.

\section{Pilot study}

Before starting survey, a pilot study was conducted. The author decided upon the contents of questionnaires through discussion with medical staff at clinics, and with researchers of mental health and psychiatric nursing, and natural product users. Subsequently, two psychiatric outpatients who met the inclusion criteria tested the self-reported questionnaires and discussed the comprehensibility of the questionnaires with the author. The final version of the questionnaire was completed by revising the original version after discussion with patients.

\section{Twelve-month use of natural products}

In this study, natural products were defined as a group consisting of the following four types: supplements/health foods, herbal tea, aromatherapy and Kampo. Prescribed product (e.g., prescribed Kampo) was not included in the definition of natural products in this study in order to focus on complementary health approaches.

Detailed support documentation that contains definitions of complementary health approaches and each natural product with examples, was enclosed with the questionnaire. In the document, natural products were described as follows: "A supplement/ health food is not categorized as regular food and includes vitamins, minerals, herbs, etc.," "Herbal tea is a brewing of dried herbs," "Aromatherapy is a type of naturopathy using essential oils," "Kampo includes prescribed Kampo and over-the-counter Kampo (sold at pharmacy or shop)."

The prevalence of natural product use was assessed by the following question for each natural product (i.e., supplements/ health foods, herbal tea, aromatherapy and Kampo): "The following are questions regarding complementary health approaches. Did you use natural products (i.e., supplements/ health foods, herbal tea, aromatherapy and Kampo) in the past 12 months?" In the case of only Kampo, one more question which we prepared was used in order to exclude prescribed products from natural products: "Circle if you have used: prescribed Kampo."

The state of natural product use was assessed by asking four further questions: having information about safety and effects before the use of natural products; feeling benefit from the use of natural products; experienced side effects from natural products; and reported the use of natural products to a psychiatrist.

\section{Sociodemographic characteristics}

Sociodemographic variables measured in the questionnaires included sex (male or female), age (categorized as 20-34, 35-49, 50-64 and 65+ years old), education (0-11, 12, 13-15 and 16+ years), marital status (married, separated-widowed-divorced and never married), employment (working or non-working), household income (yen) $(<2.5$ million, 2.5-4.4 million, 4.5-6.9 million, 7.0 million+, unknown), smoking, drinking, religion, limited activity of daily living (ADL) (No: "I can act without any limits" or Yes: "Symptoms inhibit activity of daily living, I lie down more than half of the day, or I lie down all day"), use of other treatment/support programs such as day treatment center, backto-work program or self-help group, and self-reported diagnoses.

\section{Medication adherence}

Medication adherence was assessed using the Self-Reported Medication-Taking Scale that was developed by Morisky et al.[21], a four-item measure of self-reported level of medication adherence. The four-items include: forgetting ("Do you ever forget to take your medicine?"), carelessness ("Are you careless at times about taking your medicine?"), stopping the drug when feeling better ("When you feel better do you sometimes stop taking your medicine?") and stopping the drug when feeling worse ("Sometimes if you feel worse when you take the medicine, do you stop taking it?"). These are rated with a 1 (Yes) or 0 (No). The reliability and validity of the English version of the Self-Reported Medication-Taking Scale have been confirmed [21]. Kamishima et al., developed a Japanese version by translation and backtranslation with permission from the original author [22].

\section{Statistical methods}

Statistical analyses were conducted for respondents who were 
prescribed any medications and answered without missing any questions. Respondents who reported any type of natural product use were regarded as natural product users. Multiple logistic regression analysis was conducted to determine associations (odds ratio, ORs) between sociodemographic characteristics (i.e., sex, age, education, marital status, employment, household income, smoking, drinking, religion, limited activity of daily living (ADL) and use of other treatment/support programs) and natural product use, using these demographic characteristic variables simultaneously in the model. A variable of self-reported diagnoses was not included in predictive factors of the logistic regression analysis in this study. Because it was difficult to select the diagnoses for many respondents who had multiple symptoms. The associations (ORs) between medication adherence and natural product use were also examined by multiple logistic regressions, adjusting for sociodemographic variables. All the analyses were conducted with PROC FREQ and PROC LOGISTIC from the Statistical Analysis System (SAS) 9.4 for Windows statistical package (SAS Institute Inc., Casey, North Carolina, USA).

\section{Ethical considerations}

The participants were given documents that explained the aims and procedures, voluntary nature of cooperation, and anonymity of the study by the medical staff in clinics or the author. The participants were informed about the contents of the document in writing or verbally. Respondents gave their consent by submitting the self-administered questionnaires. After respondents completed the questionnaires, they put their questionnaires into an envelope individually and anonymously, and the sealed envelope was dropped into a collection box that the author prepared to maintain confidentiality.

\section{Results}

Two hundred and forty-one patients in two clinics answered the questionnaire (response rate, 95\%). Statistical analysis was conducted for 189 respondents after excluding data from respondents who were not prescribed any medications $(\mathrm{N}=5)$ and data that included any missing questions $(\mathrm{N}=48$, there was one overlapping).

\section{Characteristics of respondents}

Demographic characteristics of the total respondents, users and non-users of natural products are shown in Table 1. The number of respondents using natural products was 104 (55\%): supplements/health foods (such as vitamin, sesamin, etc.) (41\%), herbal tea (20\%), aromatherapy (16\%), and over-thecounter Kampo (Japanese herbal medicines) (8\%) (Table 2).The most frequent diagnoses were mood disorder (53\%), substance use disorder (22\%), sleep disorder (15\%) and anxiety disorder (13\%) (Multiple answers allowed).

\section{Side effects, and reporting to a psychiatrist about the use of natural products}

No respondents who used supplements/health foods or aromatherapy, $5 \%$ of herbal tea users and $13 \%$ of over-thecounter Kampo users, answered that they experienced side effects due to natural product use (Table 2).

More than $80 \%$ of natural product use was not reported to their psychiatrists by the users: $17 \%$ of supplement/health foods use, $8 \%$ of herbal tea use, $20 \%$ of aromatherapy use and $13 \%$ of over-the-counter Kampo use were reported to psychiatrists by the users respectively (Table 2).

\section{Sociodemographic correlates of natural product use in the past 12 months}

Associations between demographic variables and the use of natural products are shown in Table 3. Respondents who were female (OR: 4.28, 95\% CI: 1.87-9.77, p < .001) or having any religion (OR: 2.91, 95\% CI: 1.10-7.68, $\mathrm{p}=.031$ ) were significantly associated with natural product use. Respondents aged 65 years or older had a significantly smaller probability of using natural products (OR: .15, 95\% CI: .03-.78, $\mathrm{p}=.024$ ).

\section{Medication adherence and natural product use}

Association between medication adherence measured by using the Self-Reported Medication-Taking Scale and natural product use are shown in Table 4. Among the respondents who reported carelessness with prescribed medications and stopping the drug when feeling worse, natural product users were significantly fewer (OR: .24, 95\% CI: .08-.76, p = .015; OR: .11, 95\% CI: .02-.69, $\mathrm{p}=.018$ ).

\section{Discussion}

This is the first study to illustrate the frequency and characteristics of natural product use and the association between natural product use and medication adherence in psychiatric outpatients in Japan. It was found that $55 \%$ of respondents used natural products. Significant association with natural product use were being female and having any religion. Respondents aged 65 years or older had a significantly smaller probability of using natural products. Most natural product use had not been reported to their psychiatrist. Among the respondents who reported carelessness with prescribed medications and stopping the drug when feeling worse, natural product users were significantly fewer.

\section{Frequency and characteristics of natural product use for complementary health approaches}

This study delineates commonly used natural products for complementary health approaches in the past 12 months among Japanese psychiatric outpatients. Specifically, more than half of psychiatric outpatients used natural products.

Of the natural products, supplements/health foods were the most popular and were used by $41 \%$ of respondents. Other studies for outpatients in clinics other than psychiatry or community-living people in Japan also showed similar results, which indicated that the most popular natural product among Japanese was supplements (23 to 47\%)[2-5]. In comparison, many studies outside Japan reported that people used herbal therapies more than supplements[10-15]. In Japan, supplements and health foods are regarded as foods and sold in grocery shops 
Table 1: Demographic characteristics of total respondents, users and non-users of natural products (NPs) in a cross-sectional survey of psychiatric outpatients in Japan

\begin{tabular}{|c|c|c|c|c|c|c|}
\hline & \multicolumn{2}{|c|}{ Total respondents $(n=189)$} & \multicolumn{2}{|c|}{ NP users $(n=104)$} & \multicolumn{2}{|c|}{ NP non-users $(n=85)$} \\
\hline & $\mathbf{n}$ & $\%$ & $\mathbf{n}$ & $\%^{a}$ & $\mathbf{n}$ & $\%^{a}$ \\
\hline \multicolumn{7}{|l|}{ Sex } \\
\hline Male & 110 & 58 & 51 & 49 & 59 & 69 \\
\hline Female & 79 & 42 & 53 & 51 & 26 & 31 \\
\hline \multicolumn{7}{|l|}{ Age (years old) } \\
\hline $35-49$ & 83 & 44 & 48 & 46 & 35 & 41 \\
\hline $50-64$ & 51 & 27 & 29 & 28 & 22 & 26 \\
\hline $65+$ & 23 & 12 & 7 & 7 & 16 & 19 \\
\hline$($ mean \pm SD) & \multicolumn{2}{|c|}{$(47.0 \pm 13.9)$} & \multicolumn{2}{|c|}{$(45.1 \pm 11.9)$} & \multicolumn{2}{|c|}{$(49.4 \pm 15.7)$} \\
\hline
\end{tabular}

Education (years)

\begin{tabular}{|c|c|c|c|r|r|r|}
\hline $0-11$ years & 33 & 17 & 11 & 11 & 22 \\
\hline 12 years & 45 & 24 & 29 & 28 & 16 \\
\hline $13-15$ years & 27 & 14 & 14 & 13 & 13 \\
\hline $16+$ years & 84 & 44 & 50 & 48 & 34 \\
\hline
\end{tabular}

Marital status

\begin{tabular}{|c|c|c|c|c|c|c|}
\hline Married & 78 & 41 & 49 & 47 & 29 \\
\hline Separated/widowed/divorced & 33 & 17 & 13 & 13 & 20 \\
\hline Never married & 78 & 41 & 42 & 40 & 36 \\
\hline
\end{tabular}

Employment

\begin{tabular}{|c|c|c|c|c|r|r}
\hline Working & 83 & 44 & 52 & 50 & 31 & 36 \\
\hline Non-working & 106 & 56 & 52 & 50 & 54 & 64 \\
\hline
\end{tabular}

Household income (yen/year)

\begin{tabular}{|c|c|c|c|c|c|c|}
\hline$<2.5$ million & 76 & 40 & 33 & 32 & 43 \\
\hline $2.5-4.4$ million & 28 & 15 & 18 & 17 & 10 \\
\hline $4.5-6.9$ million & 27 & 14 & 20 & 19 & 12 \\
\hline 7.0 million+ & 39 & 21 & 26 & 25 & 7 \\
\hline Unknown & 19 & 10 & 7 & 12 & 7 \\
\hline
\end{tabular}

Smoking

\begin{tabular}{|l|l|l|l|l|l|l|}
\hline No & 111 & 59 & 67 & 64 & 44 \\
\hline Yes & 78 & 41 & 37 & 36 & 41 \\
\hline
\end{tabular}

Drinking

\begin{tabular}{|c|c|c|c|r|r|r|r|}
\hline No & 144 & 76 & 74 & 71 & 70 \\
\hline Yes & 45 & 24 & 30 & 29 & 15 \\
\hline
\end{tabular}

Religion

\begin{tabular}{|c|c|c|c|c|c|c|}
\hline No & 157 & 83 & 81 & 78 & 76 & 89 \\
\hline Yes & 32 & 17 & 23 & 22 & 9 & 11 \\
\hline \multicolumn{7}{|c|}{ Limited activity of daily living (ADL) } \\
\hline No & 102 & 54 & 61 & 59 & 41 & 48 \\
\hline Yes & 87 & 46 & 43 & 41 & 44 & 52 \\
\hline \multicolumn{7}{|c|}{ Use of other treatment/ support programs } \\
\hline No & 117 & 62 & 64 & 62 & 53 & 62 \\
\hline Yes & 72 & 38 & 40 & 38 & 32 & 38 \\
\hline
\end{tabular}

${ }^{\text {a }}$ The percentage indicates the proportion of NP users and non-NP users among total respondents for each category. 
Table 2: Pre-use information, benefit, side effect, and reporting to a psychiatrist of the use of natural products (NPs) by the type of NP among psychiatric outpatients in Japan

\begin{tabular}{|c|c|c|c|c|c|c|c|c|c|c|}
\hline \multirow[t]{2}{*}{ Type of NPs } & \multicolumn{2}{|c|}{$\begin{array}{c}\text { Prevalence of } N P \\
\text { use among all } \\
\text { respondents }(n=189)^{a}\end{array}$} & \multicolumn{2}{|c|}{$\begin{array}{l}\text { Having information } \\
\text { about safety and effects } \\
\text { before use of NPs }\end{array}$} & \multicolumn{2}{|c|}{$\begin{array}{l}\text { Feeling benefit from } \\
\text { the use of NPs }\end{array}$} & \multicolumn{2}{|c|}{$\begin{array}{l}\text { Experienced side } \\
\text { effects from NPs }\end{array}$} & \multicolumn{2}{|c|}{$\begin{array}{c}\text { Reported the } \\
\text { use of NPs to a } \\
\text { psychiatrist }\end{array}$} \\
\hline & $\mathrm{n}$ & $\%$ & $\mathrm{n}$ & $\%^{\mathrm{b}}$ & $\mathrm{n}$ & $\%^{\mathrm{b}}$ & $\mathrm{n}$ & $\%^{\mathrm{b}}$ & $\mathrm{n}$ & $\%^{\mathrm{b}}$ \\
\hline $\begin{array}{l}\text { Supplement/health } \\
\text { foods }\end{array}$ & 77 & 41 & 45 & 58 & 27 & 35 & - & - & 13 & 17 \\
\hline Herbal tea & 38 & 20 & 13 & 34 & 14 & 37 & 2 & 5 & 3 & 8 \\
\hline Aromatherapy & 30 & 16 & 17 & 57 & 19 & 63 & - & - & 6 & 20 \\
\hline $\begin{array}{l}\text { Over-the-counter } \\
\text { Kampo }\end{array}$ & 16 & 8 & 9 & 56 & 9 & 56 & 2 & 13 & 2 & 13 \\
\hline \multicolumn{11}{|c|}{$\begin{array}{l}\text { A total of } 104 \text { respondents (55\%) reported the use of any of the four NPs. } \\
\text { The percentage indicates the proportion of users of each type of NPs who endorsed the item above. } \\
\text { - No case }\end{array}$} \\
\hline
\end{tabular}

Table 3: Association between demographic variables and the use of natural products (NPs) in psychiatric outpatients in Japan a

\begin{tabular}{|c|c|c|c|}
\hline & OR & $95 \% \mathrm{CI}$ & p-value \\
\hline \multicolumn{4}{|l|}{ Sex } \\
\hline Male & 1 & & \\
\hline Female & 4.28 & $(1.87-9.77)$ & $<0.001^{* *}$ \\
\hline \multicolumn{4}{|l|}{ Age (years old) } \\
\hline $20-34$ & 1 & & \\
\hline $35-49$ & 0.54 & $(0.19-1.56)$ & 0.253 \\
\hline $50-64$ & 0.63 & $(0.19-2.10)$ & 0.449 \\
\hline $65+$ & 0.15 & $(0.03-0.78)$ & $0.024^{*}$ \\
\hline \multicolumn{4}{|l|}{ Education (years) } \\
\hline $0-11$ years & 1 & & \\
\hline 12 years & 2.11 & $(0.65-6.81)$ & 0.213 \\
\hline $13-15$ years & 0.69 & $(0.17-2.79)$ & 0.607 \\
\hline $16+$ years & 1.93 & $(0.59-6.35)$ & 0.278 \\
\hline \multicolumn{4}{|l|}{ Marital status } \\
\hline Married & 1 & & \\
\hline Separated/widowed/divorced & 0.54 & $(0.17-1.70)$ & 0.293 \\
\hline Never married & 0.51 & $(0.20-1.32)$ & 0.163 \\
\hline \multicolumn{4}{|l|}{ Employment } \\
\hline Working & 1 & & \\
\hline Non-working & 0.91 & $(0.41-1.99)$ & 0.808 \\
\hline \multicolumn{4}{|l|}{ Household income (yen/year) } \\
\hline$<2.5$ million & 1 & & \\
\hline 2.5-4.4 million & 1.97 & $(0.65-5.97)$ & 0.23 \\
\hline 4.5-6.9 million & 3.16 & $(0.97-10.23)$ & 0.056 \\
\hline 7.0 million+ & 1.59 & $(0.51-4.89)$ & 0.424 \\
\hline Unknown & 0.76 & $(0.23-2.52)$ & 0.65 \\
\hline \multicolumn{4}{|l|}{ Smoking } \\
\hline No & 1 & & \\
\hline
\end{tabular}


Use of Natural Products for Complementary Health Approaches among Psychiatric Outpatients in Japan

\begin{tabular}{|c|c|c|c|}
\hline Yes & 0.91 & $(0.44-1.89)$ & 0.808 \\
\hline \multicolumn{4}{|l|}{ Drinking } \\
\hline No & 1 & & \\
\hline Yes & 2.39 & $(1.00-5.73)$ & 0.05 \\
\hline \multicolumn{4}{|l|}{ Religion } \\
\hline No & 1 & & \\
\hline Yes & 2.91 & $(1.10-7.68)$ & $0.031 *$ \\
\hline \multicolumn{4}{|c|}{ Limited activity of daily living (ADL) } \\
\hline No & 1 & & \\
\hline Yes & 0.61 & $(0.30-1.24)$ & 0.173 \\
\hline \multicolumn{4}{|c|}{ Use of other treatment /support programs } \\
\hline No & 1 & & \\
\hline Yes & 1.26 & $(1.58-2.74)$ & 0.559 \\
\hline \multicolumn{4}{|c|}{$\begin{array}{l}\text { adds ratio (OR), the } 95 \% \text { confidence interval }(95 \% \mathrm{CI}) \text { and } \mathrm{p} \text {-value estimated by using multiple logistic regression with entering all demographic } \\
\text { variables in the model. } \\
{ }^{*} \mathrm{p}<.05,{ }^{* *} \mathrm{p}<.01\end{array}$} \\
\hline
\end{tabular}

Table 4: Association between medication adherence measured by using the Self-Reported Medication-Taking Scale and natural product (NP) use

\begin{tabular}{|c|c|c|c|c|c|c|c|c|c|}
\hline & \multicolumn{2}{|c|}{$\begin{array}{l}\text { Total respondents } \\
\text { (n=189) }\end{array}$} & \multicolumn{2}{|c|}{ NP users $(n=104)$} & \multicolumn{2}{|c|}{ NP non-users $(n=85)$} & \multirow[b]{3}{*}{$\mathrm{OR}^{\mathrm{b}}$} & \multirow[b]{3}{*}{$95 \% \mathrm{CI}^{\mathrm{b}}$} & \multirow[b]{3}{*}{$\mathrm{p}$-value ${ }^{\mathrm{b}}$} \\
\hline & $\mathbf{N}$ & $\%^{a}$ & $\mathbf{N}$ & $\%^{a}$ & $\mathbf{N}$ & $\%^{a}$ & & & \\
\hline \multicolumn{7}{|l|}{ Forgetting } & & & \\
\hline No & 76 & 40 & 42 & 40 & 34 & 40 & 1 & & \\
\hline Yes & 113 & 60 & 62 & 60 & 51 & 60 & 0.98 & $(0.46-2.11)$ & 0.957 \\
\hline
\end{tabular}

\begin{tabular}{c|c|c|c|c|c|c|c|c|c|} 
Carelessness \\
\hline No & 163 & 86 & 96 & 92 & 67 & 79 & 1 & \\
\hline Yes & 26 & 14 & 8 & 8 & 18 & 21 & 0.24 & $(0.08-0.76)$ & $0.015^{*}$ \\
\hline
\end{tabular}

Stopping the drug when feeling better

\begin{tabular}{|c|c|c|c|c|c|c|c|c|c|}
\hline No & 165 & 87 & 90 & 87 & 75 & 88 & 1 & \\
\hline Yes & 24 & 13 & 14 & 13 & 10 & 12 & 2.46 & $(0.77-7.86)$ & 0.127 \\
\hline
\end{tabular}

${ }^{a}$ All respondents were prescribed any medication. The percentage indicates the proportion of respondents who endorsed each category of the SelfReported Medication-Taking Scale among the total respondents, NP users and NP non-users.

${ }^{\mathrm{b}}$ Odds ratio (OR), the $95 \%$ confidence interval $(95 \% \mathrm{CI}$ ) and p-value of NP use associated with each category of the Self-Reported Medication-

Taking Scale were estimated by using multiple logistic regression adjusting for all demographic variables (i.e., sex, age, education, marital status, employment, household income, smoking, drinking, religion, limited activity of daily living (ADL), use of other treatment/support programs) in the model. $*$ p $<.05$

without any legal regulations controlling supplement sales. Therefore, it is easier to obtain supplements and health foods compared to non-prescribed herbal medicines. This might have influenced the higher frequency of supplements/health foods use in Japan.

The frequency of use of herbal tea (20\%), and aromatherapy $(16 \%)$ in this study exceeds that of herbs and aromatherapy use in Japanese community-living people in the study by Fukuda et al. in 2006[5]. The reported frequency of aromatherapy or herbs was $2 \%$ in male and $7.1 \%$ in female [5]. One of the possible reasons for the higher frequency of herbal tea and aromatherapy use in 2016 in comparison to the findings in 2006 is because herbal teas and aromatherapy has become more familiar to Japanese in the last 10 years. Another reason may be due to the characteristics of symptoms among respondents. The most frequent diagnoses of the respondents in this study were neuropsychiatric 
symptoms such as anxiety, depression and sleep disorder. It is reported that people who have neuropsychiatric symptoms use more complementary health approaches than people without neuropsychiatric symptoms $[13,15,16,19]$. On account of this, the frequencies of use of herbal tea and aromatherapy among psychiatric outpatients in this study might have been higher than the findings from Fukuda et al. among community-living people other than psychiatric patients.

From the findings of this study, the frequency of experiencing side effects of herbal tea, aromatherapy and over-the-counter Kampo were 5, 0, and 13\%, respectively, and were similar to experience of side effects with Kampo (12\%) and aromatherapy/ herbal therapy (3\%) among patients who have severe chronic disease in Japan in 2015[8]. The same study reported that $13 \%$ experienced side effects from supplements/health foods [8], interestingly, no one reported side effects from supplements in this study, which may be attributable to that respondents used mild natural products in the present study, such as vitamins.

This study showed a lower number for reporting natural product use to their psychiatrists compared to $23 \%$ for those reporting use to physicians in Japanese family medicine clinics[2]. Some reasons for not reporting their natural product use to their doctors are reported. According to Robinson et al., one of the reasons might be that patients felt it unnecessary to report such use to doctors [9]. Many psychiatric patients in this study might also feel that it is not necessarily to report their natural product use to their doctors.

\section{Demographic characteristics of natural product use}

Female gender was significantly associated with natural product use. This result is similar to previous studies among psychiatric patients in the U.S [12,13,15-17].

Older respondents had a smaller probability of using natural products in this study and this was similar to a nationwide study among community-living people in the U.S [15]. Younger psychiatric patients might have a preference for active health related behavior such as natural products use compared to older patients.

Respondents who have any religion use natural products more than respondents who did not have any religion. People who believe in religion might have associated health-related values and beliefs, and may use numerous approaches related to health. Mohammad et al. also demonstrated such health-related values and beliefs were factors in the use of complementary health approaches [23]

\section{Medication adherence and natural product use}

Natural product users reported less carelessness with prescribed medications and not stopping the drug when feeling worse. In other words, natural product users tend to be careful about medications and continuing taking medications even if they are in poor condition. That is to say, natural product users attitudes toward some aspects of conventional medicine were more adherent than non-users. This is similar to findings among psychiatric outpatients in Taiwan in 2005[18]. They found that complementary health approach users were more likely to visit psychiatrist and clinics [18]. The use of natural products might be one of the help-seeking behaviors for psychiatric outpatients who use natural products. They might utilize both natural products and prescribed medications proactively to improve their own condition. This may be a reason for why medication adherence for natural product users was higher in this study.

\section{Limitations}

This study has several limitations. First, participants were recruited at only two psychiatric clinics in Tokyo. These clinics focus especially on treatment for patients having substance use disorders and patients who aim to return to work, respectively. Consequently, many respondents in this study had substance use, mood, sleep or anxiety disorders. Therefore, the diagnostic distribution in this study was specific, for instance there are a few respondents who were diagnosed with schizophrenia, and this study may not represent general psychiatric outpatients in Japan. Second, we could not recruit natural product users who were not using psychiatric care and had stopped going to outpatient clinics. Future research that includes various respondents, who have difficulties related to mental health, including people who are not receiving any psychiatric treatments, is required.

\section{Conclusion}

In conclusion, more than one in two psychiatric outpatients in Japan used some form of natural products such as supplements and herbs for their mental or physical health. Natural product users reported being more careful with prescribed medications, while only a few reported the use of natural products to psychiatrists. Many health care providers may not be aware of patient natural product use. Health care providers had better communicate with patients about the use, the effects and any possible risks of natural products for patients' safe and good relationship between patients and health care providers.

\section{Acknowledgments}

This study was supported from the Department of Mental Health/Psychiatric Nursing at The University of Tokyo. The authors thank all of the participants and staff members for their cooperation without which this study would not have been possible. The authors report no financial relationships with commercial interests.

\section{Declarations}

\section{Ethical approval}

There are no conflicts of interest. The aims and procedures of this study were approved by the Research Ethics Committee of the Graduate School of Medicine, The University of Tokyo (Approval No. 11228, 2016 / 7 / 29).

\section{References}

1. National Center for Complementary and Integrative Health. Complementary, Alternative, or Integrative Health: What's In a Name? 2016. 
2. Shumer G, Warber S, Motohara S, Yajima A, Plegue M, Bialko M, et al. Complementary and alternative medicine use by visitors to rural Japanese family medicine clinics: results from the international complementary and alternative medicine survey. BMC Complement Altern Med. 2014;14:360. Doi:10.1186/1472-6882-14-360

3. Hori s, mihaylov i, vasconcelos jc, mccoubrie m, et al. Patterns of complementary and alternative medicine use amongst outpatients in Tokyo, japan. Bmc complement altern med. 2008; 8:14. doi:10.1186/1472-6882-8-14

4. Kajiyama h, akama h, yamanaka h, shoji a, matsuda y, tanaka e, et al. One third of japanese patients with rheumatoid arthritis use complementary and alternative medicine. Mod rheumatol 2006;16(6):355-9.doi:10.1007/s10165-006-0521-3

5. Fukuda S, Watanabe E, Ono N, Tsubouchi M, Shirakawa T. Use of complementary and alternative medicine and health problems (in Japanese). Nihonkōshū eisei zasshi (Japanese Journal of Public Health).2006; 53(4): 293-300.

6. Jacobsson I, Jönsson AK, Gerdén B, Hägg S. Spontaneously reported adverse reactions in association with complementary and alternative medicine substances in Sweden. Pharmacoepidemiol Drug Saf. 2009;18(11):1039-47.Doi:10.1002/pds.1818

7. Tsutani K, Yukawa K, Nagasawa M, Arai I, Igarashi A, Orikasa H, et al. Survey on Health Hazards Indirectly Caused by Complementary and Alternative Medicine in Japan (in Japanese). Yakuri to chiryō (Japanese Pharmacology and Therapeutics). 2014;42(12):1005-14.

8. Yukawa K, Ishikawa H, Yamazaki Y, Tsutani K, Kiuchi T.Relationship between health literacy and coping behavior towards the side effects of complementary and alternative medicine among patients with chronic diseases in Japan (in Japanese). Nihon kenkō kyōiku gakkaishi(Japanese Society of Health Education and Promotion)).2015;23(1):16-26. Doi:10.11260/kenkokyoiku.23.16 Doi: $10.11260 /$ kenkokyoiku.23.16

9. Robinson A, McGrail MR. Disclosure of CAM use to medical practitioners: a review of qualitative studies. Complement Ther Med. 2004;12(2-3):90-8. Doi:10.1016/j.ctim.2004.09.006

10. Bahceci B, Bagcioglu E, Ozturk A, Bulbul F, Sahiner IV, Tuncer BE, et al. Complementary and alternative medicine use in patients with mental disorders in Turkey. Complement Ther Clin Pract 2013;19(4):221-226.Doi: 10.1016/j.ctcp.2013.06.005

11.Wu P, Fuller C, Liu X, Lee HC, Fan B, Hoven CW, et al. Use of complementary and alternative medicine among women with depression: results of a national survey. Psychiatr Serv. 2007;58(3):349-356. Doi: 10.1176/ps.2007.58.3.349

12.Choi NG, Kim J. Utilization of complementary and alternative medicines for mental health problems among Asian Americans. Community Ment Health J. 2010; 46(6): 570-8. Doi:10.1007/s10597010-9322-4
13.Woodward AT, Bullard KM, Taylor RJ, Chatters LM, Baser RE, Perron BE, et al. Complementary and alternative medicine for mental disorders among African Americans, black Caribbeans, and whites. Psychiatr Serv. 2009;60(10): 1342-9. Doi:10.1176/ ps.2009.60.10.1342

14. Hsu MC, Moyle W, Creedy D, Venturato L, Ouyang WC, Tsay SL. Use of antidepressants and complementary and alternative medicine among outpatients with depression in Taiwan. Arch Psychiatr Nurs. 2009;23(1):75-85. Doi: 10.1016/j.apnu.2008.03.004

15. Ravven SE, Zimmerman MB, Schultz SK, Wallace RB. 12-month herbal medicine use for mental health from the national Comorbidity Survey Replication (NCS-R). Ann Clin Psychiatry. 2011;23(2):83-94. 16.Purohit MP, Wells RE, Zafonte RD, Davis RB, Phillips RS. Neuropsychiatric symptoms and the use of complementary and alternative medicine. Pm r. 2013; 5(1): 24-31. Doi:10.1016/j. pmrj.2012.06.012

17. Bazargan M, Ani CO, Hindman DW,Bazargan-Hejazi S, Baker RS, Bell D, et al. Correlates of complementary and alternative medicine utilization in depressed, underserved African American and Hispanic patients in primary care settings. J Altern Complement Med. 2008;14(5):537-44. Doi:10.1089/acm.2007.0821

18. Pan JJ, Chen BY, Teng HW, Lu ML, Shen WW. The use of alternative medicine among Taiwanese psychiatric outpatients. Psychiatry Clin. Neurosci. 2005;59(6):711-716. Doi:10.1111/j.14401819.2005.01441.x

19. Feng L, Chiam PC, Kua EH, Ng TP. Use of complementary and alternative medicines and mental disorders in community-living Asian older adults. Arch Gerontol Geriatr. 2010;50(3):243-9.

20.Weiden PJ, Kozma C, Grogg A, Locklear J. Partial compliance and risk of rehospitalization among California Medicaid patients with schizophrenia. Psychiatr Serv. 2004;55(8): 886-91. Doi:10.1176/ appi.ps.55.8.886

21. Morisky DE, Green LW, Levine DM. Concurrent and predictive validity of a self-reported measure of medication adherence. Med Care. 1986;24(1):67-74.

22.Kamishima S, Noji A, Katakura Y, Maruyama T.Factors Related to Adherence to a Medication Regimen in Out-patients Being Treated for Stroke (in Japanese). Nihon kango kagaku gakkaishi (Journal of JapanAcademy of Nursing Science). 2008; 28(1): 21-30.Doi:10.5630/ jans.28.1_21

23.Siahpush M. Why do people favour alternative medicine? Aust N Z J Public Health. 1999;23(3):266-271. 